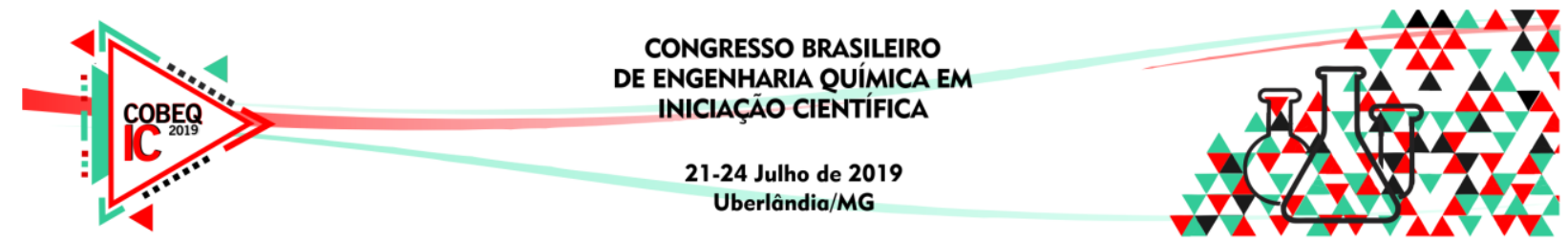

\title{
CARACTERIZAÇÃO DE FILMES POLIMÉRICOS COM ADIÇÃO DE POLPA DE PITAYA VERMELHA (Hylocerus Polyrhizus)
}

\author{
J. K. ABREU ${ }^{1}$ A. B. REIS ${ }^{1}$
}

${ }^{1}$ Universidade Federal dos Vales do Jequitinhonha e Mucuri, Instituto de Ciência e Tecnologia (UFVJM) - Curso de Engenharia Química.

E-mail para contato: julliakoury97@gmail.com

\begin{abstract}
RESUMO - A Pitaya é um fruto de cactos epífitos do gênero Hylocereus, podendo ser encontradas mais facilmente em território brasileiro em duas diferentes espécies: Pitaya Branca (Hylocereus undatus) casca vermelha e polpa branca e a pitaya vermelha (Hylocerus Polyrhizus) e polpa vermelha. O objetivo do trabalho foi confeccionar filmes poliméricos com adição de polpa de pitaya vermelha afim de detectar possíveis propriedades da polpa que ao serem inseridas nos filmes, dê ao mesmo características relevantes para futuras confecções de embalagens ativas. Foram confeccionadas três formulações distintas: a primeira formulação contendo somente quitosana $2 \%$ (em massa); a segunda formulação contendo quitosana $2 \%$ acrescido de $1 \mathrm{~mL}$ de polpa; a terceira formulação contendo quitosana $2 \%$, acrescida de $5 \mathrm{~mL}$ de polpa. Afim de realizar a caracterização das três formulações de filmes, foram realizadas as seguintes análises: Espessura, Permeabilidade ao Vapor D’água (PVA), teor de umidade e solubilidade em água. Ao final, observou-se que a adição de diferentes concentrações de polpa alterou as características dos filmes biopoliméricos.
\end{abstract}

\section{INTRODUÇÃO}

Pitaya é uma fruta exótica natural de cactos epífitos, e por essa característica não necessita de irrigação continua para se desenvolver. Em território brasileiro são conhecidos cerca de 36 gêneros e aproximadamente 230 espécies, e que são cultivadas de várias formas como plantas ornamentais e comestíveis. Entre as espécies comestíveis a espécie que foi utilizada na elaboração da pesquisa foi a pitaya vermelha (Hylocerus Polyrhizus) caracterizada por ter a casca vermelha e polpa vermelha. Além disso, a pitaya é rica nos pigmentos naturais betalaínas que possuem atividade antioxidante e potencial para serem extraídos e utilizados na indústria alimentícia e cosmética (ADNAN; OSMAN; HAMID, 2011; ESQUIVEL; STINTZING; CARLE, 2007; SUH et al., 2014). A capacidade antioxidante da pitaya é dada principalmente pela presença de compostos como o ácido ascórbico, carotenóides e polifenóis, sendo essa ação benéfica bastante visada para combater o estresse oxidativo no corpo, prevenindo doenças degenerativas (ABREU et al., 2012; COSTA, 2012). 


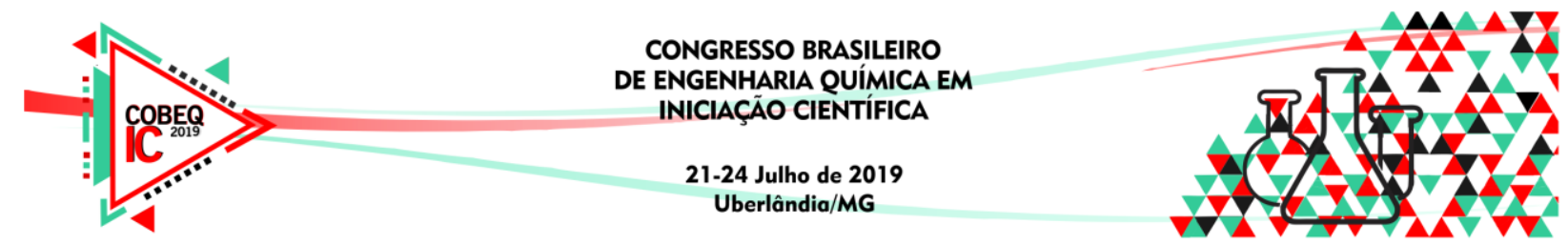

A betalaína, presente tanto na casca quanto na polpa da pitaya, é um pigmento solúvel em água e contém ácido betalâmico em sua estrutura. Esse pigmento é conhecido pela sua coloração avermelhada e amarelo-alaranjado, assim como pelas propriedades antioxidante, anti-inflamatória e quimiopreventiva (GARCÍA-CRUZ et al., 2013)

Figura 1 - Fotos de frutos da pitaya vermelha

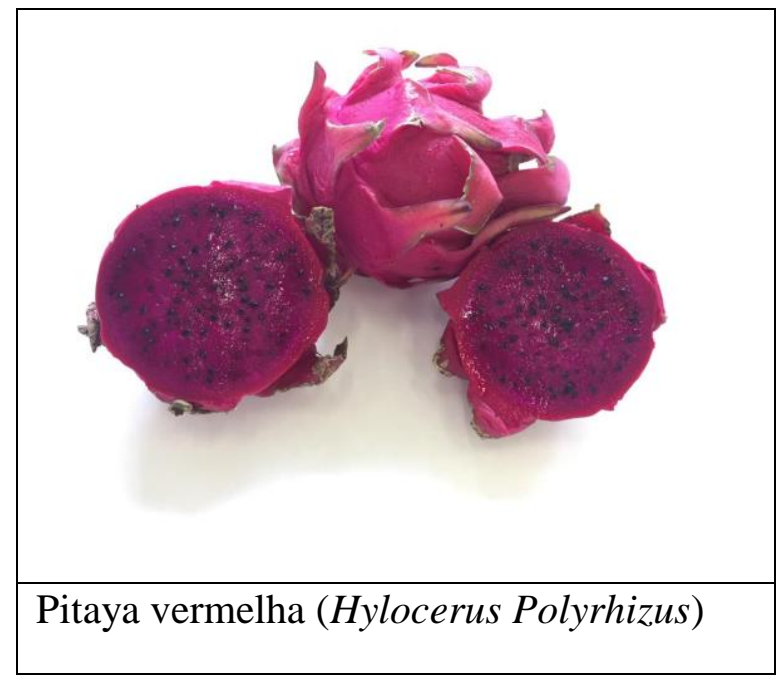

As pitayas se diferem em tamanho, formato e cor da polpa. A polpa da pitaya vermelha, tem um tom avermelhado bem acentuado. Portanto, chama-se a atenção para o uso da polpa da pitaya vermelha como agente colorante. A incorporação de corantes naturais, sensíveis às alterações de $\mathrm{pH}$, pode representar uma alternativa ao uso de corantes sintéticos na elaboração de embalagens ativas. Esses corantes podem detectar o decaimento do frescor dos alimentos, fornecendo informações a respeito da qualidade do produto. Os corantes naturais apresentam numerosas vantagens comparados aos corantes sintéticos, tal como o baixo custo, não toxicidade e renovabilidade (SHAHID, ISLAM e MOHAMMAD, 2013).

\section{MATERIAL E MÉTODOS}

Nessa seção são retratados os materiais e a metodologia empregada nas práticas laboratoriais para a realização do presente trabalho, desenvolvido no Laboratório de Engenharia do Bioprocessos e Tecnologia Ambiental, vinculado ao curso de Engenharia Química da UFVJM, campus JK-Diamantina/MG.

\subsection{Materiais}

- Amostras de pitaya cultivadas na horta situada no Campus JK- Diamantina/MG, coordenado pela Professora Doutora Maria do Céu Monteiro Cruz, pertencente ao curso de Agronomia da UFVJM, e responsável pelo Laboratório de Fruticultura da universidade. 


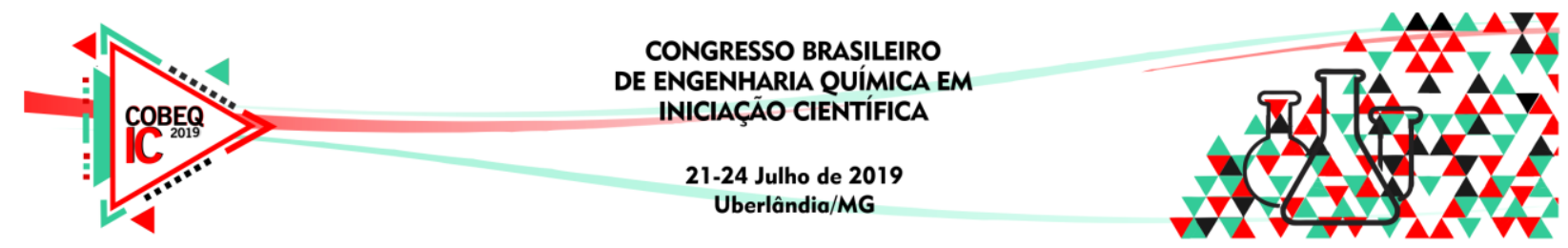

- Quitosana (Polymar - Brasil); Ácido Acético (Synth); Água deionizada; NaCl, Sílica gel;

- Placas de petri descartáveis;

- Dessecadores;

- Recipientes em acrílico ( $5 \mathrm{~cm}$ altura x 0,0027cm-diâmetro).

\subsection{Métodos}

Os filmes de quitosana foram produzidos com adição da polpa da pitaya vermelha, nas proporções $1 \%, 5 \%$, (em massa) de polpa, respectivamente, adicionadas em solução filmogênica de quitosana ( $2 \%$ em massa). As soluções filmogênicas são preparadas, com adição de quitosana, ácido acético, água deionizada e em seguida é adicionado a quantidade determinada de polpa. Essa solução é colocada em um béquer e durante 1 hora é deixada em agitação magnética. Após esse tempo, as soluções são distribuídas em placas de petri, na proporção de $20 \mathrm{~mL}$ por placa e submetidas à secagem à $45^{\circ} \mathrm{C}$ em estufa de circulação forçada durante $36 \mathrm{~h}$ horas. Logo após esse processo, os filmes foram submetidos a análise de PVA, análise de teor de umidade e solubilidade em água, considerando filmes contendo somente solução filmogênica de quitosana $2 \%$, como filmes padrão.

\subsection{Análise de Espessura}

A espessura foi obtida com micrômetro (Insize $\pm 0,001$ ) em cinco pontos de cada filme e os resultados expresso em milímetros (mm). De acordo com os procedimentos utilizados para análise de PVA ASTM E96-95 (ASTM, 1995).

\subsection{Análise de Permeabilidade ao Vapor D’Água - PVA}

A permeabilidade ao vapor d'água foi determinada pelo método ASTM E96-95 (ASTM, 1995), que corresponde a técnica gravimétrica, onde as amostras foram afixadas na parte superior de um recipiente que continha o dessecante (sílica gel azul). Cinco sistemas foram acondicionados num dessecador com temperatura ambiente e umidade relativa controladas (solução de $\mathrm{NaCl}$ saturada, com umidade relativa correspondente à $75 \%$ ). A massa final foi feita após 5 dias de estocagem do sistema, e então foi determinado o valor de massa adquirida, correspondente a diferença entre a massa inicial e a massa final do sistema.

Os sistemas foram submetidos a uma temperatura ambiente e temperatura controlada $\left(25^{\circ} \mathrm{C}\right.$ e $75 \%$, respectivamente). Ao final de cinco dias, a massa final foi obtida, e assim foi determinado o valor de massa adquirida, que é a diferença entre a massa inicial e a massa final do sistema. A permeabilidade foi obtida através a equação 1.

$$
P V A=\frac{\Delta m x \text { espessura filme }}{\text { Aamostrax } \Delta t \Delta p} \times 100
$$

Onde $\Delta m$ é massa ganha, Aamostra corresponde a área do filme, $\Delta p$ é a diferença de pressão parcial (mantida constante com valor de $2,3 \mathrm{KPa}$, levando em consideração localidade de produção dos filmes) e $\Delta t$ é a média de realização do experimento. 


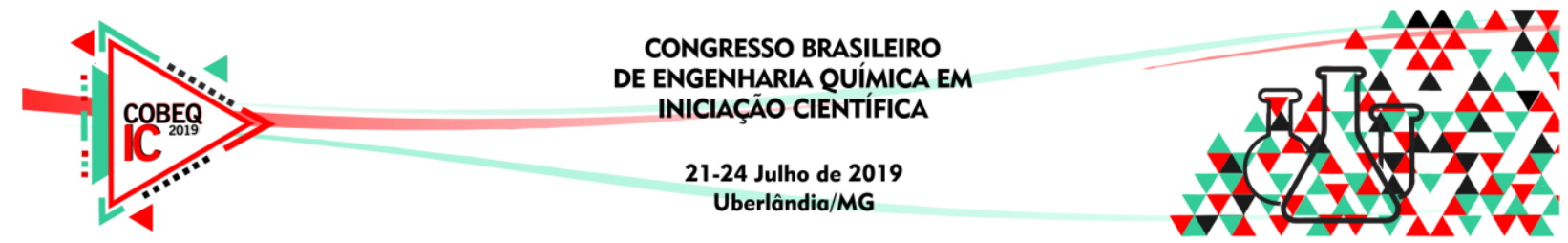

\subsection{Teste de teor de umidade}

A determinação do teor de umidade é importante uma vez que, a umidade se caracteriza pela perda de peso sofrida em condições nas quais a água é removida. Por isso é necessário verificar que o que está sendo evaporado é apenas água e com isso, os demais componentes presentes permanecem. Essa determinação foi realizada de acordo com (MOURA et al., 2014). As amostras foram cortadas aleatoriamente e distribuídas em recipientes de alumínio devidamente tarados que, em seguida foram armazenados em estufa a $105^{\circ} \mathrm{C}$ durante 24 horas. Os ensaios foram feitos em triplicata e as amostras foram pesadas até que atingissem peso constante. Os resultados foram expressos em porcentagem de acordo com equação 2 .

$$
\%=\frac{m \text { final }-m \text { inicial }}{m \text { inicial }} \times 100
$$

\subsection{Análise de solubilidade em água}

A análise de solubilidade foi realizada de acordo com os trabalhos de Zamundio et.al (2010). As amostras de filme ( $2 \mathrm{~g}$ ) foram cortadas em dimensões $(1 \mathrm{~cm} \times 2 \mathrm{~cm})$ e armazenadas sob UR $=0 \%$ durante sete dias. Após esse período as amostras foram submersas em $80 \mathrm{~mL}$ de água deionizada e mantidas a temperatura ambiente sob agitação contínua durante 1 hora. Decorrido esse tempo, as amostras foram expostas a secagem em estufa á $60^{\circ} \mathrm{C}$. $\mathrm{O}$ cálculo da análise de solubilidade em água é feito de acordo com a equação 3.

$$
\%=\frac{m \text { inicial }-m \text { final }}{m \text { inicial }} \times 100
$$

\section{RESULTADOS E DISCUSSÃO}

Após a realização de todos os procedimentos seguindo detalhadamente todas as instruções contidas nas bibliografias consultadas. Os resultados dos testes realizados com os filmes produzidos utilizando a polpa da pitaya vermelha estão contidos na tabela 1 . 


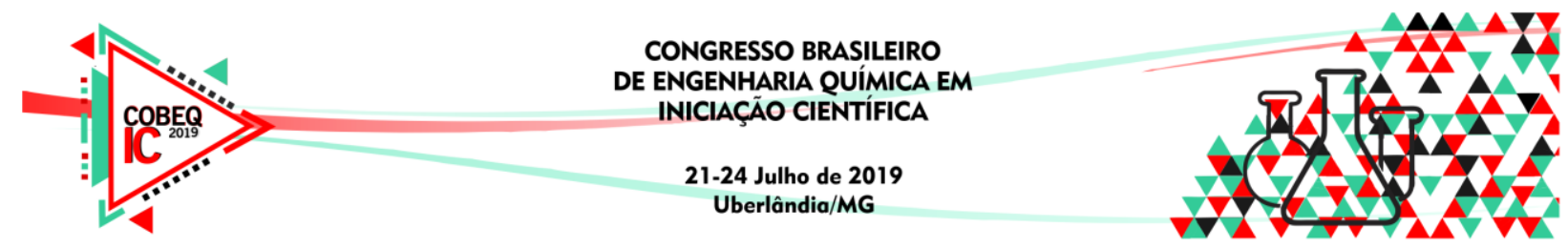

Tabela 1- Resultados dos testes de espessura, solubilidade em água, permeabilidade ao vapor d'água e teor de umidade dos filmes produzidos nas diferentes concentrações

\begin{tabular}{|l|l|l|l|l|}
\hline \multirow{2}{*}{$\begin{array}{c}\text { Amostras Filmes } \\
\text { Composição }\end{array}$} & \multicolumn{4}{|c|}{ Análises } \\
\cline { 2 - 5 } & $\begin{array}{l}\text { Espessura } \\
(\mathrm{mm})\end{array}$ & $\begin{array}{l}\text { Solubilidade } \\
(\%)\end{array}$ & $\begin{array}{l}\text { WVP } \\
(\mathrm{gmm} / \mathrm{hm} 2 \mathrm{KPa})\end{array}$ & $\begin{array}{l}\text { Teor de } \\
\text { umidade (\%) }\end{array}$ \\
\hline Quitosana 2\% (massa) & $0,045 \pm 0,001$ & $11,91 \pm 0,1$ & $0,076 \pm 0,025$ & $14,97 \pm 0,1$ \\
\hline Quitosana 2\%+1 mLpolpa & $0,064 \pm 0,001$ & $23,09 \pm 0,1$ & $0,069 \pm 0,010$ & $03,19 \pm 0,1$ \\
\hline Quitosana 2\%+5mL polpa & $0,083 \pm 0,001$ & $70,13 \pm 0,1$ & $0,060 \pm 0,010$ & $28,58 \pm 0,1$ \\
\hline
\end{tabular}

*WVP: permeability to water vapor (Permeabilidade ao Vapor d'Água)

Analisando esses resultados observa-se que à medida que a concentração da polpa inserida na produção dos filmes aumenta, há um aumento significativo da espessura do filme e também da sua solubilidade em água. Em paralelo, sabendo que a permeabilidade através do filme é determinada por diversos fatores, incluindo a morfologia, densidade, estrutura química, cristalinidade e orientação polimérica e além disso o tipo de solvente, o plastificante e a taxa de secagem também influenciam o coeficiente de permeabilidade, justifica os resultados obtidos no teste de PVA, que mostrou que a medida que a concentração da polpa aumenta, o valor do PVA diminui. Quanto aos resultados de teor de umidade, nota -se uma variância nos valores obtidos, isso mostra que a polpa quando adicionada em pequenas concentrações como $1 \mathrm{ml}$ apresenta menor teor devido as propriedades obtidas, porém em quando em excesso essas propriedades se alteram ocasionando maior umidade do filme.

\section{CONCLUSÃO}

Ao final do desenvolvimento de toda a metodologia aplicada, alguns pontos foram observados, a começar pela cor adquirida pelos filmes. Os filmes com adição de polpa apresentaram tonalidade diferente após aquecimento devido a degradação das betalaínas por isomerização, descarboxilação ou clivagem, resultando numa redução gradual do vermelho e o aparecimento de uma cor castanho claro. Além disso, quanto maior a concentração da polpa adicionada aos filmes, mostrou um aumento na espessura dos mesmos, consequentemente menor PVA e atividade em água e maior solubilidade. Consequentemente, a partir dos resultados obtidos, confirma-se a presença de propriedades que gerariam uma melhoria na qualidade e na produção de embalagens ativas, quando incorporadas ao biopolímero quitosana.

\section{REFERÊNCIAS}




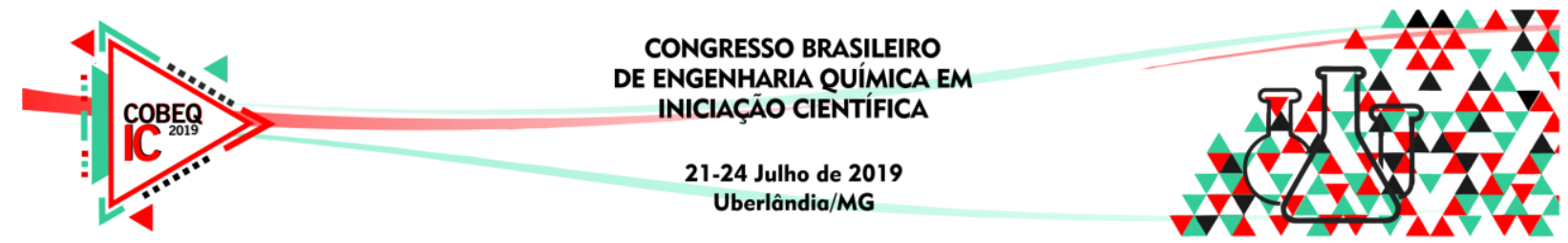

1. ABREU, W. C. et al. Características físico-químicas e atividade antioxidante total de pitaias vermelha e branca. Rev Inst Adolfo Lutz, São Paulo, v. 71, n. 4, p. 656-61, 2012.

2. ADNAN, L.; OSMAN, A.; HAMID, A. A. Antioxidant activity of different extracts of red pitaia (Hylocereus polyrhizus) seed. Int J Food Prop, New York, v. 14, p. 1171-1181, 2011.

3. AMERICAN SOCIETY FOR TESTING AND MATERIALS-ASTM Book of Standards, Philadelphia, PA. ASTM E96-00 - Standard test methods for determining gas permeability characteristics of plastic film and sheeting, 1995.

4. AMERICAN SOCIETY FOR TESTING AND MATERIALS-ASTM Book of Standards, Philadelphia, PA. ASTM E96/E 96M-05. Standard Test Methods for water vapor transmission of materials, 2005.

5. ESQUIVEL, P.; STINTZING, F. C.; CARLE, R. Phenolic compound profiles and their corresponding antioxidant capacity of purple pitaya (Hylocereus sp.) genotypes. J Biosci, Bangalore, v. 62, n. 9, p. 636-644, 2007.

6. GARCIA-CRUZ, L. et al. Physical, chemical and antioxidant activity characterization of Pitaya (Stenocereus pruinosus) Fruits. Plant Foods Hum Nutr, Dordrecht, v. 68, n. 4, p. 403-410, 2013.

7. MELLO. F.R.; BERNARDO.C.; DIAS.C.O.; GONZAGA.L.; AMANTE.E.R; FETT.R.; CANDIDO.LM.B. Propriedades antioxidantes, quantificação e estabilidade de betalaínas de pitaya (undatus). 2014.

8. ROCHA.L; GODOY.R; CUNHA.C. Estudo de alguns compostos bioativos das pitayas de polpas branca e vermelha (Cereus undatus, Sinonímia: Hylocereus guatemalensis, H.undatus). 2012.

9. SHAHID, M.; ISLAM, S.; MOHAMMAD, F. Recent advancements in natural dye applications: a review. Journal of Cleaner Production, v. 53, p.310-331, 2013.

10. ZAMUDIO-FLORES, P.B.; TORRES, A.V.; SALGADO-DELGADO, R.; BELLO-PÉREZ, L.A.Influence of the oxidation and acetylation of banana starch on the mechanical and water barrier properties of modifies starch/chitosan blend films. Jounal of Applied Polymer Science, v.115 p. 991998, 2010. 